\title{
Drug dosage in isolated limb perfusion: evaluation of a limb volume model for extremity volume calculation
}

\author{
Lars Erik Podleska ${ }^{*}$, Thorsten Poeppel ${ }^{2}$, Michael Herbrik ${ }^{3}$, Lisa Dahlkamp ${ }^{1}$, Florian Grabellus ${ }^{4}$ and Georg Taeger ${ }^{5}$
}

\begin{abstract}
Background: Exact drug dosing in isolated limb perfusion (ILP) and infusion (ILI) is essential. We developed and evaluated a model for calculating the volume of extremities and compared this model with body weight- and height-dependent parameters.
\end{abstract}

Methods: The extremity was modeled by a row of coupled truncated cones. The sizes of the truncated cone bases were derived from the circumference measurements of the extremity at predefined levels $(5 \mathrm{~cm})$. The resulting volumes were added. This extremity volume model was correlated to the computed tomography (CT) volume data of the extremity (total limb volume). The extremity volume was also correlated with the patient's body weight, body mass index (BMI) and ideal body weight (IBW). The no-fat CT limb volume was correlated with the circumference-measured limb volume corrected by the ideal-body-weight to actual-body-weight ratio (IBW corrected-limb-volume).

Results: The correlation between the CT volume and the volume measured by the circumference was high and significant. There was no correlation between the limb volume and the bare body weight, BMI or IBW. The correlation between the no-fat CT volume and IBW-corrected limb volume was high and significant.

Conclusions: An appropriate drug dosing in ILP can be achieved by combining the limb volume with the simple circumference measurements and the IBW to body-weight ratio.

Keywords: TNF-alpha, Melphalan, Volumetry, Sarcoma, Regional perfusion, Isolated limb perfusion, Drug dosage

\section{Background}

In light of the increasing incidence of obesity, there is an ongoing debate about the correct dosing of systemic chemotherapy and alternative weight models for the calculation of drug dosage [1,2]. For the treatment of locally advanced soft tissue sarcoma and malignant melanoma in the extremities, isolated limb perfusion with TNF-alpha and melphalan has proven to be one of the most effective treatment modalities with limb salvage rates of approximately $80 \%$ for soft tissue sarcoma [3-8] and local response rates of $90 \%$ for malignant melanoma [9-11].

Similar to systemic chemotherapy, the correct drug dosing is of great importance for isolated limb perfusion

\footnotetext{
* Correspondence: lars.podleska@uk-essen.de

'Department of Trauma Surgery and Musculoskeletal Surgical Oncology,

University Hospital of Essen and Sarcoma Center at the West German Cancer Center (WTZ), University of Duisburg-Essen, Hufelandstr. 55, D-45122

Essen, Germany

Full list of author information is available at the end of the article
}

and isolated limb infusion, especially with TNF-alpha and melphalan (TM-ILP), to ensure the ideal balance of the maximum therapeutic effects with the lowest regional toxicity [12-15].

The majority of authors recommend determining the drug dosage according to the limb volume as first proposed by Wieberdink et al. [16,17]. There are some alternative dosage models that have been developed, such as dosage by body weight [18] and dosage by ideal body weight [19-21].

Though many recent articles do not explicitly mention the underlying drug dosage model, dosage according to the limb volume seems to be the leading dosage model. Measurements for the limb volume are acquired either by the original water displacement method described by Wieberdink or by circumference measurements, which are still performed in many European ILP centers, including our own $[14,19]$.

\section{Biomed Central}


Another alternative for exact volumetry is computed tomography (CT) scanning. CT scanning is most often used in liver transplantation and offers fast and accurate measurement of the organ volume [22-25]. Several authors have also described the use of CT scanning for volumetry in isolated limb perfusion (ILP)/isolated limb infusion (ILI), but due to the high cost and the radiation exposure, CT scanning for volumetry has not gained wide acceptance, despite its high accuracy.

Due to the high incidence of compartment syndrome at our institution between January 2011 and July 2011, we started investigating all possible factors that could influence compartment syndrome, including our drug dosage model. Since we do know from Deroose and coauthors that "dose matters" [12], we have not just chosen dose reduction to lower the risk for compartment syndrome because that would increase the risk for a reduced response of the tumor to the treatment.

Since the drug dose for melphalan was predefined (10 to $11 \mathrm{mg}$ per liters of leg volume and $13 \mathrm{mg}$ per liter of arm volume) [26,27] and only depended on the limb volume, we started our investigation by taking a closer look at the volume model used for calculating the absolute drug dosage because we believe that the exact dosage of the drugs is essential for maintaining the balance between a good response of the tumor and a low rate of local complications.

Considering the increasing interest in ILP and ILI and the number of newly developing ILP and ILI programs, we felt it was important to characterize the different drug dosage models and to develop a simple tool for estimating the limb volume and drug dosage in isolated limb perfusion.

The aim of this study was to validate a mathematical volume model for estimating the limb volume with simple circumference measurements and to compare the volume model data to weight-based drug dosage data, such as the actual body weight (ABW), body mass index (BMI) and ideal body weight (IBW). An additional aim of this study was to provide a web-based calculation tool that would allow for on- and offline calculation of standardized limb volumes [28].

\section{Methods}

We performed a retrospective analysis of our ILP database and identified all patients who received an isolated limb perfusion and a digitally archived whole body staging positron emission tomography/computed tomography $(\mathrm{PET} / \mathrm{CT})$ that included the extremity before the ILP. All patients scheduled for ILP received a pre-operative limb volume estimation according to the circumference measure. Those patients who had evaluable CT data and a completely documented limb volume estimation (by the circumference measure) were included in this study.

\section{Calculation of limb volume by circumference measure}

The limb volume for the estimation of drug dosage was calculated by a standardized circumference measurement one day before the scheduled ILP. All measurements were performed while the patient was lying in a supine position. The patients' legs were kept straight, and the arms were abducted to $90^{\circ}$ at the shoulder. The extremity was marked with a waterproof pen; beginning at the groin/axilla, a base line was drawn (Figure 1), and markings were made at intervals of $5 \mathrm{~cm}$ down to the ankle-/wrist-level. In cases where the tumor affected the hand or foot, the distal extremity was included in the measurement. Beginning at the

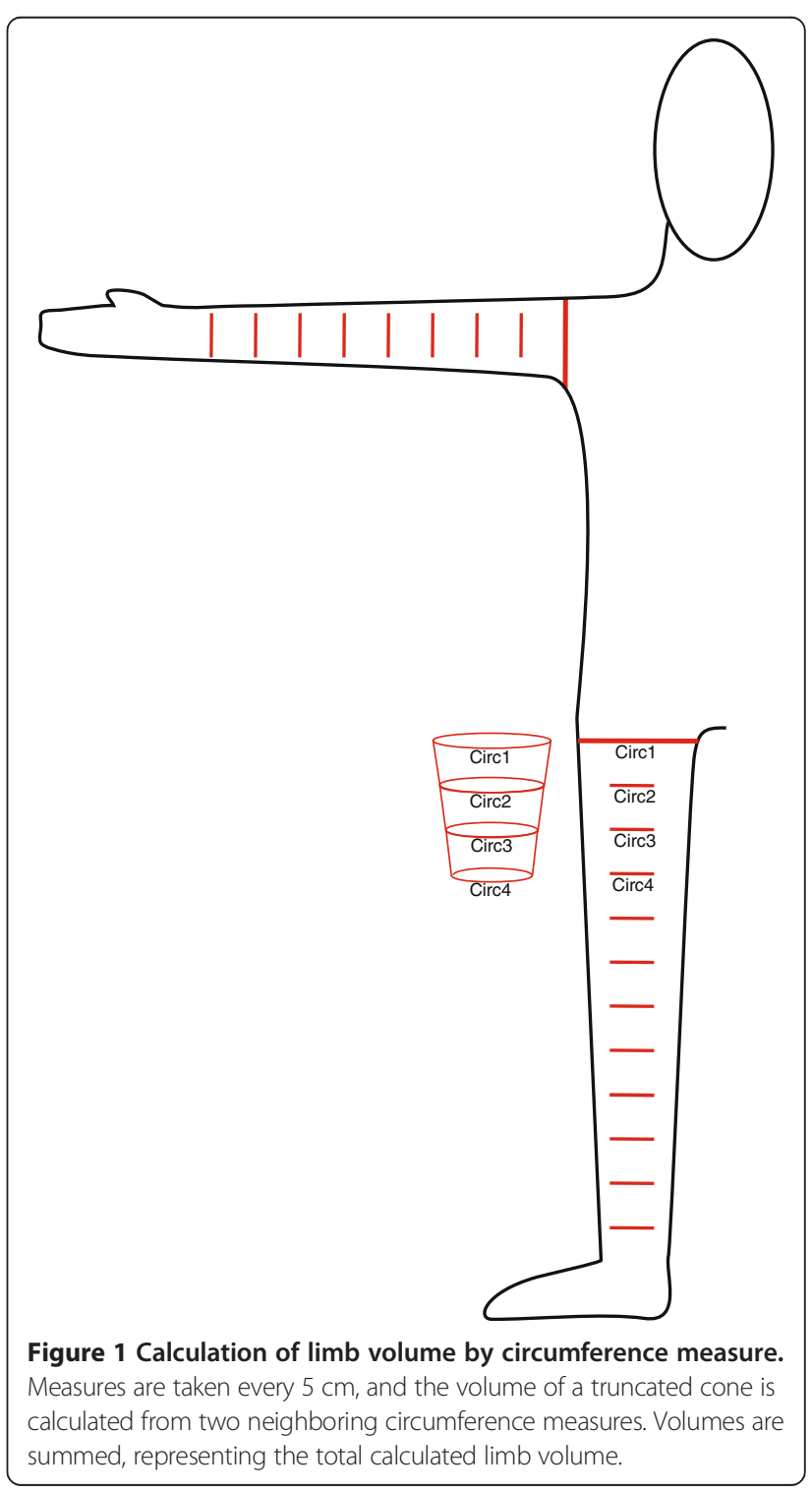


most proximal level, the circumference was measured at every $5 \mathrm{~cm}$ marking. All of the measured values were entered into an Excel-table (Microsoft Excel 2003, Microsoft, Redmond, WA, USA) or html/java-script-table [28].

The underlying calculation model was derived from a row of the frustums of a cone (Figure 1) that closely models the near circular volume of an extremity. The volume (V) of the frustum of a cone is calculated by $V=\frac{h \cdot \pi}{3} \cdot\left(\left(\frac{C i r c 1}{2 \pi}\right)^{2}+\left(\frac{C i r c 1}{2 \pi}\right) \cdot\left(\frac{C i r c 2}{2 \pi}\right)+\left(\frac{C i r c 2}{2 \pi}\right)^{2}\right)$ with $h$ being $5 \mathrm{~cm}$ (the distance for each measure), Circ1 and Circ2 being the two neighboring circumference measures. Each volume corresponds to that of a $5-\mathrm{cm}$ segment of the extremity. The sum of all volumes equals the total volume of the extremity.

A copy of the html/java-script table is available for online use. The table can also be downloaded and stored for offline use on any java-script-enabled browser [28].

\section{Estimation of limb volume by CT}

The reference limb volume for each patient was derived from CT data. Analysis was performed on the CT workstation (Syngo, Siemens AG, Berlin, Germany). As before, the proximal starting reference level was the axilla/groin, and the measurement was carried down to the wrist/ankle. As before, the distal extremity was included in the measurement in cases in which the tumor location was in the hand or foot. The extremity volume was derived from automatic data segmentation based on Hounsfield units (HU); the threshold was 200 HU, meaning that the surrounding air was not included, and everything above the density of $200 \mathrm{HU}$ was included. The result was checked visually, and segmentation errors were corrected manually.

Second, the "no-fat limb volume", representing the limb volume excluding the subcutaneous tissue, was measured as described above with the threshold set to $-20 \mathrm{HU}$.

\section{Correlation between CT-calculated limb volume and circumference-measured limb volume}

All calculations were performed in SPSS 20 (IBM Corporation, Armonk, NY, USA). The CT-calculated volume was correlated with the circumference-measured limb volume. The Pearson's product-moment correlation coefficient $(R)$ and its two-tailed significance were calculated. A normal distribution was tested by the onesample Kolmogorov-Smirnov test.

\section{Correlation of limb volume with body weight, BMI and IBW}

The circumference-measured limb volume was correlated with the patient's ABW, BMI and IBW. The body mass index was calculated according to the World Health Organization (WHO) definition:

$$
B M I=\operatorname{Weight}(k g) / \operatorname{Height}(m)^{2} .
$$

The ideal body weight (IBW) was calculated by:

$$
\begin{aligned}
\mathrm{IBW}(\mathrm{kg})= & 49.9+0.89 \\
& *(\operatorname{Height}(\mathrm{m})-152.4) \text { for men and } \mathrm{IBW}(\mathrm{kg}) \\
= & 45.4+0.89 \\
& *(\operatorname{Height}(\mathrm{m})-152.4) \text { for women. }
\end{aligned}
$$

Calculations were performed in separate groups for the arms and legs. Again, the Pearson's R and its twotailed significance were calculated.

\section{Correlation between limb volume corrected by ideal body weight and "no-fat CT volume"}

To overcome the dilemma of the circumference-measured limb volume matching the true limb volume while lacking the possibility of fat reduction in obese patients, we adapted a model presented by Beasley and coauthors in 2008 to fit our volume model [29]. With this adjustment, we multiplied the measured limb volume with the quotient of the ideal body weight and the actual body weight.

$$
V_{\text {corrected }}=V_{\text {measured }} \cdot \frac{I B W}{A B W}
$$

This calculation results in a new parameter, the IBWcorrected limb volume, which represents the limb volume minus any excess fat-tissue caused by obesity. This parameter was correlated with the "no-fat CT limb volume" using the Pearson's R and its two-tailed significance.

\section{Results}

\section{Patient data}

From our database, we identified 42 patients who received an isolated limb perfusion and underwent a pre-operative CT scan including the extremity. Of the 42 patients, 23 were male and 19 were female. The patients' mean age was 56.4 (20 to 81$)$ years. Thirty-two patients received a perfusion of the leg (12 iliac and 20 femoral) and 10 patients had perfusion of the arm (5 on the brachial level and 5 on the axillary level). Thirty-three (79\%) ILPs were performed due to soft tissue sarcoma (STS), 5 due to melanoma (12\%) and $4(10 \%)$ due to other tumors, including high-grade chondrosarcoma, desmoid tumor, squamous cell carcinoma of the bone and lymphoma.

\section{Correlation between circumference measure and CT measure}

The mean volume estimated by CT was $10.8( \pm 3.673)$ liters for legs and $3.21( \pm 0.932)$ liters for arms. In both cases, the volume measured according to the circumference was slightly lower at $10.3( \pm 3.219)$ liters for legs 
and $2.73( \pm 0.765)$ liters for arms. Figure 2 shows the correlation between the circumference-measured volume and the CT-measured volume. Arms and legs had a nearly perfect match with the regression line; therefore, the mathematical correlation was performed for the arms and legs in a single group. The Pearson's R was extremely high and significant $(\mathrm{r}=0.965 ; P<0.01)$.

\section{Correlation of body weight, body mass index and ideal body weight}

For all diagrams (Figures 3, 4 and 5), arms and legs were calculated separately. Figure 3 shows the correlation of the $\mathrm{ABW}$ with the limb volume (by the circumference measure). For legs, the correlation was positive and highly significant $(\mathrm{r}=0.871 ; P<0.01)$; for arms, the correlation was not statistically significant $(\mathrm{r}=0.508)$.

The correlation of the BMI and limb volume reveals a significant coherence for legs, as shown in Figure $4(\mathrm{r}=$ $0.781 ; P<0.01$ ), while the correlation was not significant for arms $(\mathrm{r}=0.263)$.

Not surprisingly, we found that the ideal body weight was the poorest predictor of the limb volume compared to the actual body weight and body mass index (Figure 5). In both cases (arm and legs), the correlation between the ideal body weight and the limb volume was not significant ( $r=0.305$ for legs; $r=0.466$ for arms), which could be due to the inability of the ideal body weight to account for the excess fat tissue in obese patients.

\section{Correction between limb volume and ideal body weight}

To overcome the dilemma of the circumference-measured limb volume matching the true limb volume while lacking the possibility of fat reduction in obese patients, the circumference-measured limb volume was corrected by the quotient of the IBW per ABW. The mean leg volume estimated by "no-fat CT" was $5.9( \pm 1.78)$ liters; the mean leg volume by IBW-corrected limb volume was $8.1( \pm 1.56)$ liters. Thus, the CT mean volume is $28 \%$ lower than the clinical volume. For arms, the "no-fat CT volume" was 1.8 $( \pm 0.75)$ liters and the IBW-corrected limb volume was 2.4 $( \pm 0.69)$ liters; thus, there was a $23 \%$ lower volume for the no-fat CT measure, which is expected because the "nofat" CT scan subtracts all subcutaneous fat-tissue (in addition to the regular, non-obese fat).

As we can see in Figure 6, the correlation between the "no-fat CT volume" and the IBW-corrected limb volume is very high. The Pearson's correlation coefficient was 0.833 and highly significant $(P<0.01)$ for both arms and legs together. As shown above for the $\mathrm{CT}$ volume compared to the circumference-measured volume, the arm volume was lower -represented by the green dots - but matches the regression line like the legs (represented by the blue dots).

\section{Discussion}

The safety of isolated limb perfusion and isolated limb infusion depends on a variety of parameters. One of these

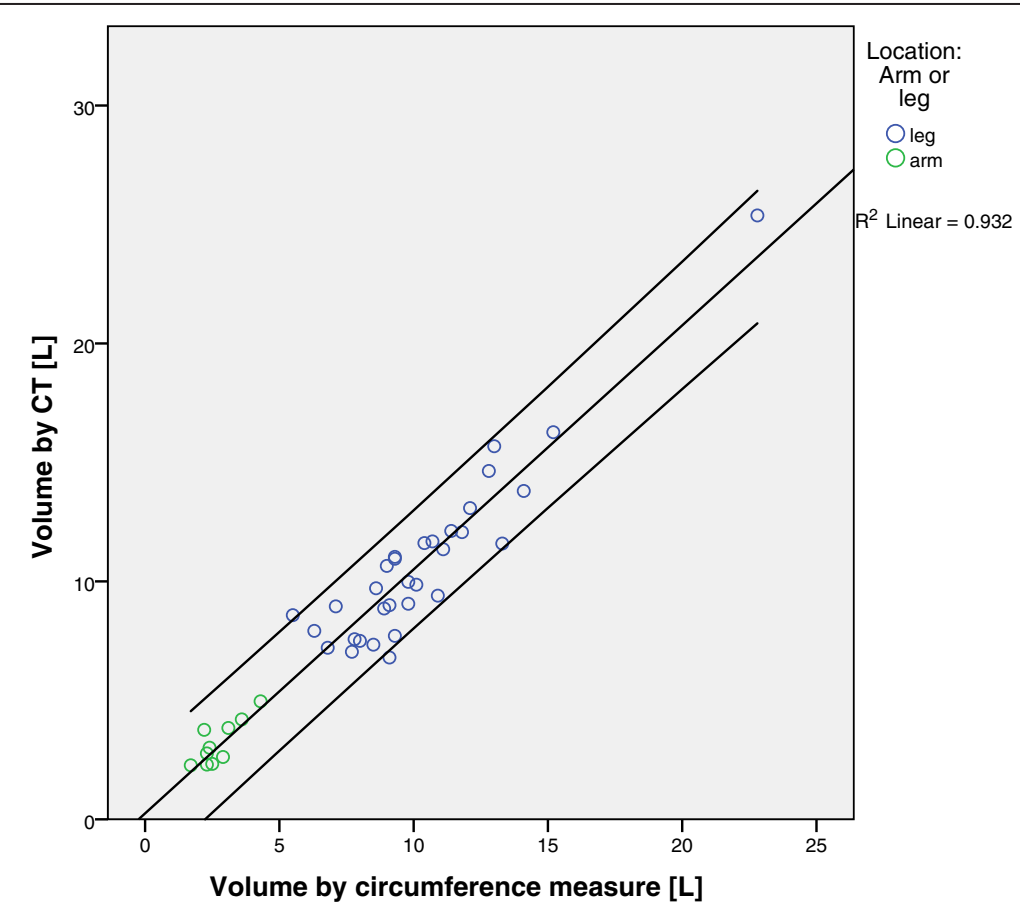

Figure $\mathbf{2}$ Correlation of limb volume measured by circumference measure and limb volume measured by CT scan. There is a very high linear correlation between the two measures. Green dots represent arms and blue dots represent legs. Note that the single dot to the far right represents a severely overweight patient who is still within the very narrow $95 \%$ confidence interval. 


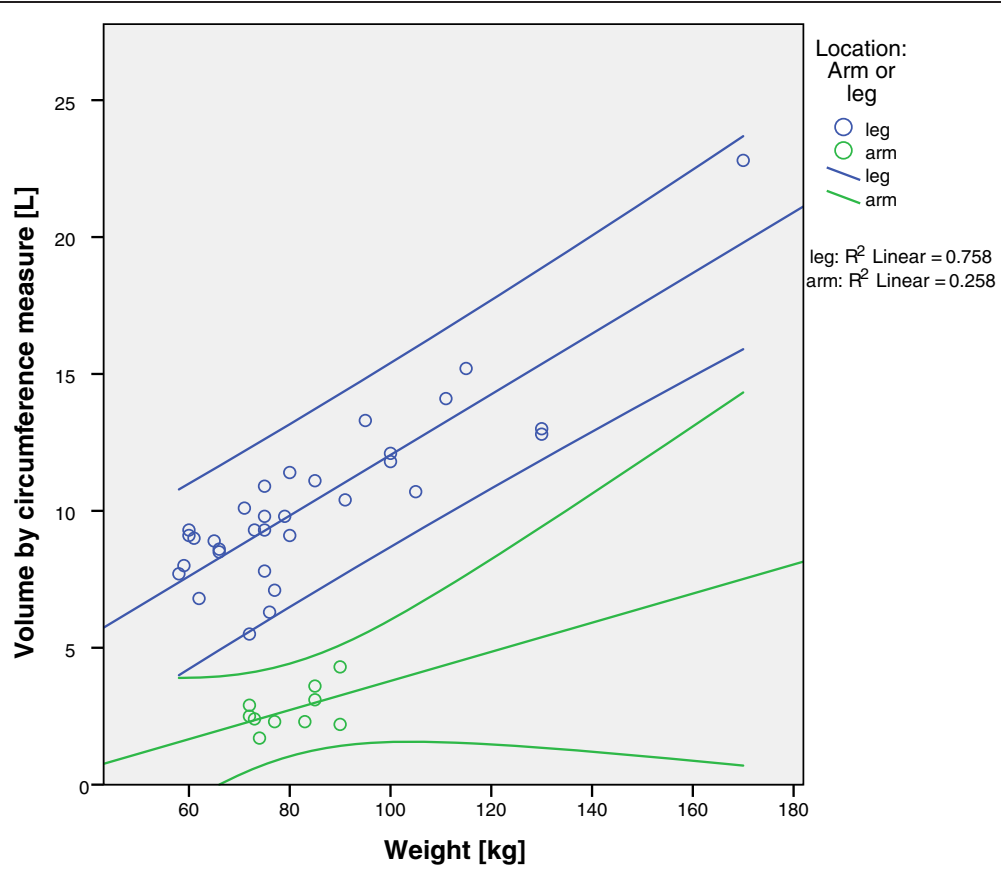

Figure 3 Correlation of body weight and limb volume by circumference measure. Green dots represent arms and blue dots represent legs. Notice that the $95 \%$ confidence intervals span a wide range.

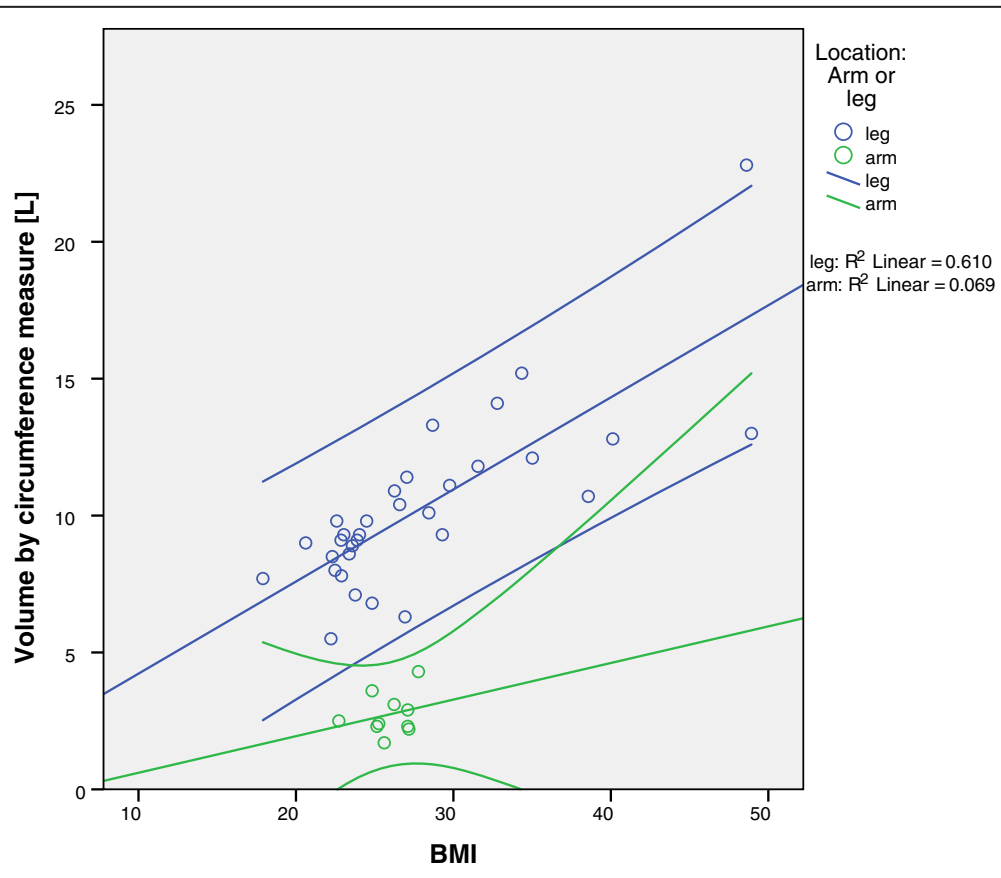

Figure 4 Correlation between BMI and limb volume by circumference measure. Green dots represent arms and blue dots represent legs. Again, the $95 \%$ confidence intervals span a wide range. 


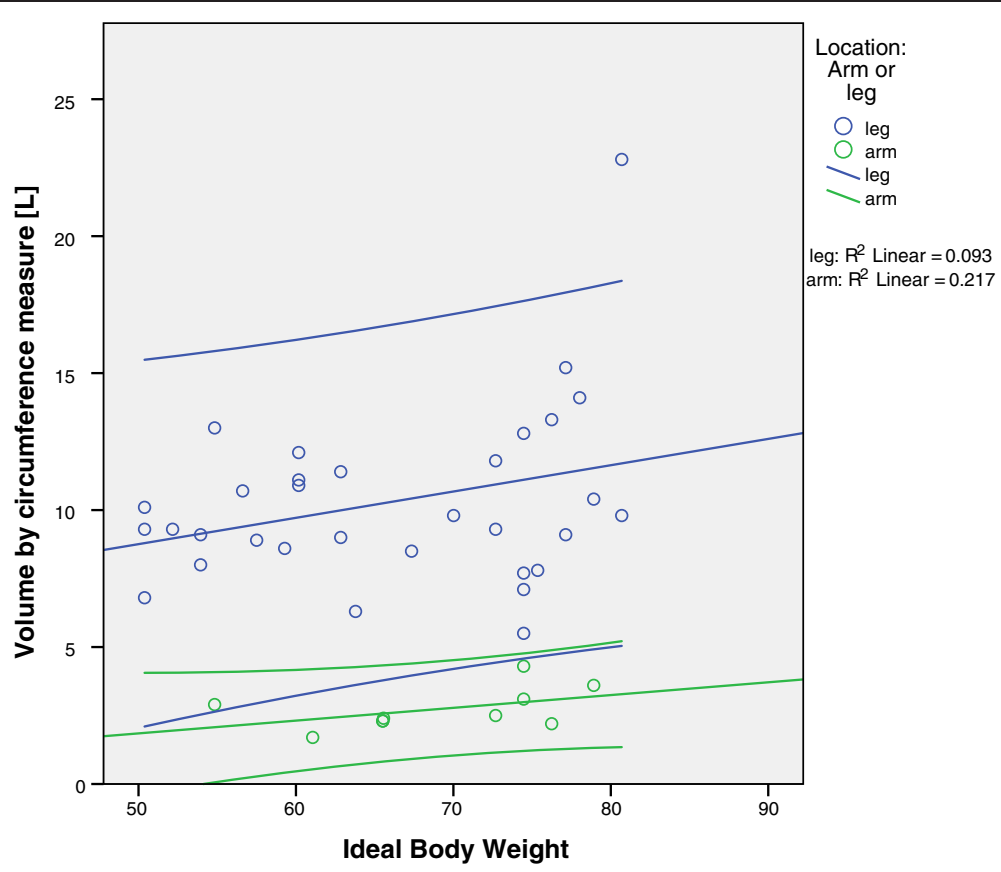

Figure 5 Correlation of IBW and limb volume by circumference measure. Green dots represent arms and blue dots represent legs. The coefficient of determination $\left(R^{2}\right)$ lies below $25 \%$ for both arms and legs, indicating that the IBW is the worst predictor for the extremity volume.

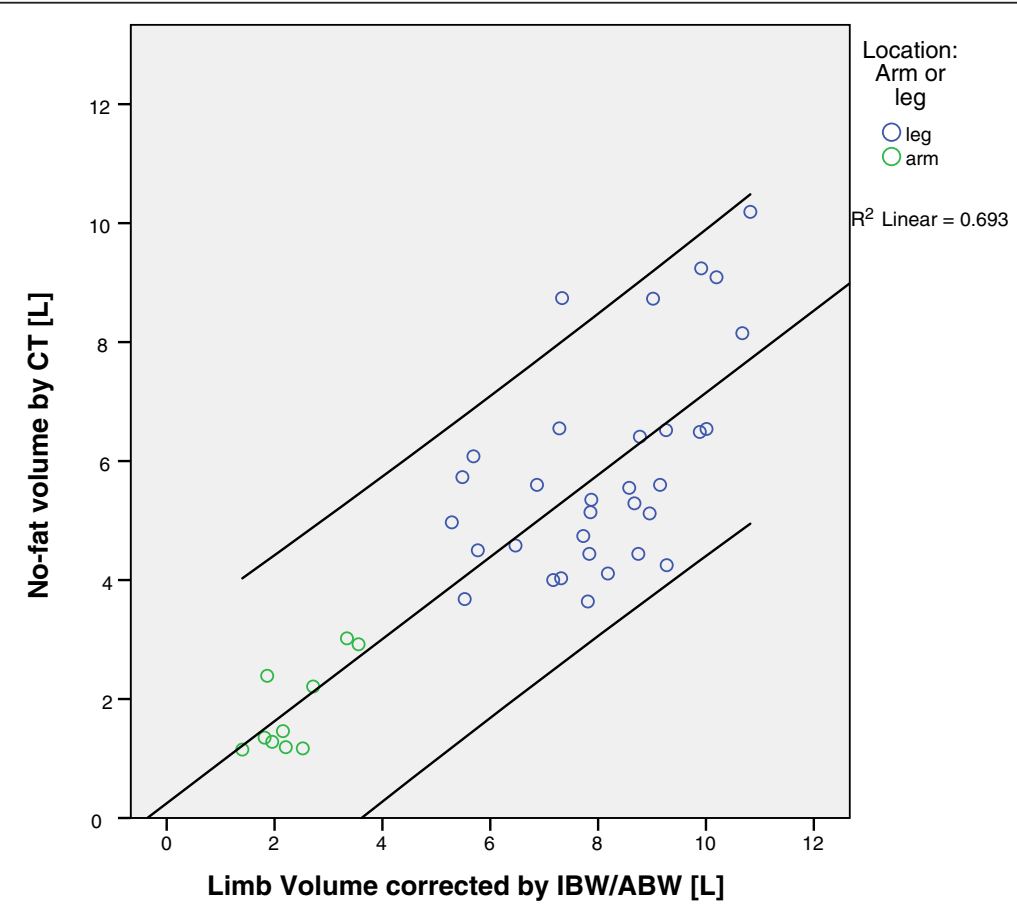

Figure 6 Correlation between circumference measured limb volume corrected with IBW/ABW-ratio and "no-fat CT volume".

The coefficient of determination $\left(R^{2}\right)$ shows that approximately $70 \%$ of all values fit the model. 
parameters is the correct dosage of the drugs administered during the procedure $[13,30]$. This is very much dependent on the volume of the extremity $[16,17]$. Arms and legs have very different limb volumes and factors such as age (especially in younger children), body weight and constitution of the patient that will ultimately affect the limb volume and recommended drug dosage. Thus, the exact dosage of the drugs is dependent on a precise volumetry of the limb in order to maintain the balance between a good response of the tumor and a low rate of local complications.

This study had the following three major aims: i.) to validate a circumference-measure volume model that was developed to allow for exact calculation of the limb volume for drug dosage in ILP; ii.) to compare body weight- and height-dependent measures to the limb volume model in terms of the accuracy of the model because the use of weight-based parameters for the dosage of drug calculation in ILP and ILI has recently become more popular $[19,20]$; and iii.) to develop a calculation tool that allows for standardized and safe volume measures and dosing of drugs in ILP and ILI.

We have shown that limb volume estimation by the circumference measure is highly reliable when compared to CT volume measurements. Even in obese patients, there is no relevant deviation in the circumference-measure volume model. In general, there is a smaller than $5 \%$ difference in the volume obtained with the circumference model and the corresponding CT-measured values. In contrast to the gold standard, the immersion method, where the extremity is immersed into a water container and the change of water level represents the exact limb volume as initially described by Wieberdink [16] has some major advantages. This method can be used for any patient, even highly immobilized or bedridden patients as Byrne and his coauthors have already described [18]. The method is cheap and easy to apply; it requires no special equipment apart from ordinary measuring tape and a personal computer with a java-script-enabled Internet browser.

Apart from the aforementioned points, there is one further advantage of note. If used with a waterproof marker pen, the circumference-measure method allows for easy dose adjustment in the femoral and brachial tourniquet placement. Because all frustums of a cone in the model are added successively, single volumes can be subtracted from the total volume, according to the true tourniquet placement in reference to the measurement markings on the patient's skin. Especially in the leg, the proximal parts can easily make up half of the limb volume, which could lead to a drastic overdose if not subtracted.

An even easier alternative to the circumference volume measures is determining the limb volume or dose calculation by body weight- or height-dependent parameters [18-20], which has been described for systemic chemotherapy $[1,2]$. When using the ideal body weight as a parameter, a possible advantage is the fact that a high amount of fat tissue (especially in obese patients) will not be excessively represented in the limb volume $[20,30]$.

As we have shown in this study, any body weight parameter by itself has a higher level of error compared to the limb volume. Especially for the arm, the deviation can easily reach $50 \%$ for patients with the same weight, BMI or IBW. In addition, as already mentioned, for femoral and brachial perfusions where the tourniquet can be placed way below the axillary or the groin level (depending on the location of the tumor), the limb volume is not actually perfused but is instead calculated by the weight, BMI or IBW models. This could account for a reduction in the perfused volume of up to $50 \%$, which would lead to a drastic overdose.

The limb volume measurement is the most reliable parameter for the perfused volume compared to the CT measures, but it lacks a sufficient method of accounting for the excess body fat in obese patients. Beasley et al. have suggested a simple way of achieving the best of both worlds; the limb volume calculated by the circumference measure can be corrected by the quotient of the ideal body weight and actual body weight [29]. For a normal weight patient, the quotient will be close to 1 , which means that the corrected volume will be equal to the actual limb volume. On the other hand, a severely obese (class III) patient will have a quotient of 0.5 or even less, which will lead to a $50 \%$ reduction of the limb volume, which is similar to what we have observed in the past by rough estimation.

In this study, we found that the limb volume measurement corrected by ideal body weight is the most appropriate method of limb volume estimation. This model shows a strong correlation with the no-fat PET-CT measures, meaning that by applying this method we achieve the best of both worlds. The individual limb volume is measured (subtract non-perfused parts of the extremity while taking high volume tumors into account) in combination with the ability to subtract only excess fatty tissue in the case of obesity.

Based on the results of this study, we have started to adopt the IBW-corrected volume model in our clinical practice. Further study is required to prove that this volume model leads to a reduction in the morbidity associated with compartment syndrome during ILP.

\section{Conclusions}

In summary, this study has proven that the limb volume estimation by the circumference measure is a highly accurate model of the true limb volume. The advantage of this model lies in how easy it is to subtract the limb volume that is not perfused from the calculation. Because the use of body weight dependent parameters, such as the body weight, BMI or IBW, alone is inaccurate for determining 
the limb volume, it is necessary to correct the limb volume with the quotient of the ideal body weight and the actual body weight. This model was transferred into an html-java-script table that is available for download and offline use [28].

\section{Abbreviations}

ABW: actual body weight; BMl: body mass index; CT: computed tomography; IBW: ideal body weight; ILP: isolated limb perfusion; ILI: isolated limb infusion PET/CT: positron emission tomography/computed tomography; TM-ILP: TNF/ Melphalan based isolated limb perfusion (in this article used synonymously with ILP); WHO: World Health Organization.

\section{Competing interests}

The authors declare that they have no competing interests.

\section{Authors' contributions}

LEP designed this study (together with GT), developed the volume model and wrote the article. TP and $\mathrm{MH}$ are responsible for the CT-based volumetry data and contributed this section of the article. LD performed the actual volume measurements, searched the files for the volume- and all patient-related data. FG helped design the study and is responsible for maintaining the ILP database and keeping it up to date. GT developed the ILP database, contributed a majority of the patients and designed this study (together with LEP). All authors read and approved the final manuscript.

\section{Author details}

'Department of Trauma Surgery and Musculoskeletal Surgical Oncology, University Hospital of Essen and Sarcoma Center at the West German Cancer Center (WTZ), University of Duisburg-Essen, Hufelandstr. 55, D-45122 Essen, Germany. ${ }^{2}$ Department of Nuclear Medicine, University Hospital of Essen, University of Duisburg-Essen, Essen, Germany. ${ }^{3}$ Department of Diagnostic and Interventional Radiology and Neuroradiology, University Hospital of Essen, University of Duisburg-Essen, Essen, Germany. ${ }^{4}$ Institute of Pathology and Neuropathology, University Hospital of Essen and Sarcoma Center at the West German Cancer Center (WTZ), University of Duisburg-Essen, Essen, Germany. ${ }^{5}$ Department of Musculoskeletal Surgical Oncology, University Hospital of Essen and Sarcoma Center at the West German Cancer Center (WTZ), University of Duisburg-Essen, Essen, Germany.

Received: 5 May 2013 Accepted: 16 March 2014

Published: 1 April 2014

\section{References}

1. Sparreboom A, Wolff AC, Mathijssen RH, Chatelut E, Rowinsky EK, Verweij J, Baker SD: Evaluation of alternate size descriptors for dose calculation of anticancer drugs in the obese. J Clin Oncol 2007, 25:4707-4713.

2. Pai MP: Drug dosing based on weight and body surface area: mathematical assumptions and limitations in obese adults. Pharmacotherapy 2012, 32:856-868.

3. Grabellus F, Kraft C, Sheu-Grabellus SY, Bauer S, Podleska LE, Lauenstein TC, Pottgen C, Konik MJ, Schmid KW, Taeger G: Tumor vascularization and histopathologic regression of soft tissue sarcomas treated with isolated limb perfusion with TNF-alpha and melphalan. J Surg Oncol 2011, 103:371-379.

4. Deroose JP, van Geel AN, Burger JW, Eggermont AM, Verhoef C: Isolated limb perfusion with TNF-alpha and melphalan for distal parts of the limb in soft tissue sarcoma patients. J Surg Oncol 2011, 105:563-569.

5. Deroose JP, Eggermont AM, van Geel AN, Burger JW, den Bakker MA, de Wilt JH, Verhoef C: Long-term results of tumor necrosis factor alpha- and melphalan-based isolated limb perfusion in locally advanced extremity soft tissue sarcomas. J Clin Oncol 2011, 29:4036-4044.

6. Taeger G, Grabellus F, Podleska LE, Müller S, Ruchholtz S: Effectiveness of regional chemotherapy with TNF-alpha/melphalan in advanced soft tissue sarcoma of the extremities. Int J Hyperthermia 2008, 24:193-203.

7. Grunhagen DJ, de Wilt JH, Graveland WJ, Verhoef C, van Geel AN, Eggermont AM: Outcome and prognostic factor analysis of 217 consecutive isolated limb perfusions with tumor necrosis factor-alpha and melphalan for limb-threatening soft tissue sarcoma. Cancer 2006, 106:1776-1784.
8. Eggermont AM, Schraffordt Koops H, Klausner JM, Kroon BB, Schlag PM, Lienard D, van Geel AN, Hoekstra HJ, Meller I, Nieweg OE, Kettelhack C, Ben-Ari G, Pector JC, Lejeune FJ: Isolated limb perfusion with tumor necrosis factor and melphalan for limb salvage in 186 patients with locally advanced soft tissue extremity sarcomas. The cumulative multicenter European experience. Ann Surg 1996, 224:756-764. discussion 764-765.

9. Deroose JP, Grunhagen DJ, van Geel AN, de Wilt JH, Eggermont AM, Verhoef C: Long-term outcome of isolated limb perfusion with tumour necrosis factor-alpha for patients with melanoma in-transit metastases. Br J Surg 2011, 98:1573-1580.

10. Deroose JP, Eggermont AM, van Geel AN, Verhoef C: Isolated limb perfusion for melanoma in-transit metastases: developments in recent years and the role of tumor necrosis factor alpha. Curr Opin Oncol 2011, 23:183-188

11. Grunhagen DJ, de Wilt JH, van Geel AN, Eggermont AM: Isolated limb perfusion for melanoma patients-a review of its indications and the role of tumour necrosis factor-alpha. Eur J Surg Oncol 2006, 32:371-380.

12. Deroose JP, Eggermont AM, van Geel AN, de Wilt JH, Burger JW, Verhoef C: 20 years experience of TNF-based isolated limb perfusion for in-transit melanoma metastases: TNF dose matters. Ann Surg Oncol 2012, 19:627-635.

13. Duprat Neto JP, Oliveira F, Bertolli E, Molina AS, Nishinari K, Facure L, Fregnani JH: Isolated limb perfusion with hyperthermia and chemotherapy: predictive factors for regional toxicity. Clinics (Sao Paulo) 2012, 67:237-241.

14. Santillan AA, Delman KA, Beasley GM, Mosca PJ, Hochwald SN, Grobmyer SR, Andtbacka RH, Noyes RD, Kane JM, Ross MI, Tyler DS, Zager JS: Predictive factors of regional toxicity and serum creatine phosphokinase levels after isolated limb infusion for melanoma: a multi-institutional analysis. Ann Surg Oncol 2009, 16:2570-2578.

15. Grunhagen DJ, de Wilt JH, van Geel AN, Graveland WJ, Verhoef C, Eggermont AM: TNF dose reduction in isolated limb perfusion. Eur J Surg Oncol 2005, 31:1011-1019.

16. Wieberdink J, Benckhuysen C, Braat RP, van Slooten EA, Olthuis GA: Dosimetry in isolation perfusion of the limbs by assessment of perfused tissue volume and grading of toxic tissue reactions. Eur J Cancer Clin Oncol 1982, 18:905-910.

17. van Os J, Schraffordt Koops H, Oldhoff J: Dosimetry of cytostatics in hyperthermic regional isolated perfusion. Cancer 1985, 55:698-701.

18. Byrne DS, McKay AJ, Blackie R, MacKie RM: A comparison of dosimetric methods in isolated limb perfusion with melphalan for malignant melanoma of the lower extremity. Eur J Cancer 2082-2087, 1996:32A.

19. McMahon N, Cheng TY, Beasley GM, Spasojevic I, Petros W, Augustine CK, Zipfel P, Padussis JC, Sanders G, Tyler DS: Optimizing melphalan pharmacokinetics in regional melanoma therapy: does correcting for ideal body weight alter regional response or toxicity? Ann Surg Oncol 2009, 16:953-961.

20. Huismans AM, Kroon HM, Haydu LE, Kam PC, Thompson JF: Is melphalan dose adjustment according to ideal body weight useful in isolated limb infusion for melanoma? Ann Surg Oncol 2012, 19:3050-3056.

21. Kam PC, Thompson JF: Isolated limb infusion with melphalan and actinomycin $D$ in melanoma patients: factors predictive of acute regional toxicity. Expert Opin Drug Metab Toxicol 2010, 6:1039-1045.

22. Heymsfield SB, Fulenwider T, Nordlinger B, Barlow R, Sones $P$, Kutner M: Accurate measurement of liver, kidney, and spleen volume and mass by computerized axial tomography. Ann Intern Med 1979, 90:185-187.

23. Luciani A, Rusko L, Baranes L, Pichon E, Loze B, Deux JF, Laurent A Tran-Van-Nhieu J, Rahmouni A: Automated liver volumetry in orthotopic liver transplantation using multiphase acquisitions on MDCT. AJR Am J Roentgenol 2012, 198:W568-W574.

24. Gao L, Heath DG, Kuszyk BS, Fishman EK: Automatic liver segmentation technique for three-dimensional visualization of CT data. Radiology 1996 , 201:359-364.

25. Frericks BB, Caldarone FC, Nashan B, Savellano DH, Stamm G, Kirchhoff TD, Shin HO, Schenk A, Selle D, Spindler W, Klempnauer J, Peitgen HO, Galanski M: 3D CT modeling of hepatic vessel architecture and volume calculation in living donated liver transplantation. Eur Radiol 2004, 14:326-333.

26. Eggermont AM, Schraffordt Koops H, Lienard D, Kroon BB, van Geel AN, Hoekstra HJ, Lejeune FJ: Isolated limb perfusion with high-dose tumor necrosis factor-alpha in combination with interferon-gamma and melphalan for nonresectable extremity soft tissue sarcomas: a multicenter trial. J Clin Oncol 1996, 14:2653-2665. 
27. Grabellus F, Kraft C, Sheu SY, Ebeling P, Bauer S, Lendemans S, Schmid KW, Taeger G: Evaluation of 47 soft tissue sarcoma resection specimens after isolated limb perfusion with TNF-alpha and melphalan: histologically characterized improved margins correlate with absence of recurrences. Ann Surg Oncol 2009, 16:676-686.

28. Extremity volume calculation tool. http://www.uk-essen.de/published/ ilp-volume-calc-tool.

29. Beasley GM, Petersen RP, Yoo J, McMahon N, Aloia T, Petros W, Sanders G, Cheng TY, Pruitt SK, Seigler H, Tyler DS: Isolated limb infusion for in-transit malignant melanoma of the extremity: a well-tolerated but less effective alternative to hyperthermic isolated limb perfusion. Ann Surg Oncol 2008, 15:2195-2205.

30. Kroon HM, Moncrieff M, Kam PC, Thompson JF: Factors predictive of acute regional toxicity after isolated limb infusion with melphalan and actinomycin D in melanoma patients. Ann Surg Oncol 2009, 16:1184-1192.

doi:10.1186/1477-7819-12-81

Cite this article as: Podleska et al.: Drug dosage in isolated limb perfusion: evaluation of a limb volume model for extremity volume calculation. World Journal of Surgical Oncology 2014 12:81.

\section{Submit your next manuscript to BioMed Central and take full advantage of:}

- Convenient online submission

- Thorough peer review

- No space constraints or color figure charges

- Immediate publication on acceptance

- Inclusion in PubMed, CAS, Scopus and Google Scholar

- Research which is freely available for redistribution 